\title{
Comparison of conventional and automated freezing methods on PB2 rooster semen cryopreserved with glycerol and dimethylsulfoxide tris coconut-water extender
}

Adedeji Suleimon Balogun ${ }^{1 *}$, Raman Narang ${ }^{1}$, Ranjna S. Cheema ${ }^{2}$, Ajeet Kumar ${ }^{2}$, Narinder Singh ${ }^{2}$ and Malik Vijaysingh $^{2}$

\begin{abstract}
Background: Poultry semen cryopreservation remains an easy and promising way of preserving and transferring poultry germplasm. Standardizing and optimizing freezing procedure with natural extender may be a reliable step towards achieving better post-thawed sperm quality. This study was conducted to investigate the effects of four different freezing protocols (FP) on frozen rooster semen extended with tris coconut water extender (TCWE). A total of 20 roosters were used and trained for semen collection. TCWE was prepared by adding coconut water to tris buffer and kept at $37^{\circ} \mathrm{C}$. Semen was collected and pooled from the roosters and was evaluated for motility before dilution procedure. Three different concentrations (8, 10, and 15\%) of two intracellular cryoprotectants glycerol and dimethylsulfoxide (DMSO) were supplemented in TCWE. Pooled semen was divided into six equal fractions, and TCWE containing cryoprotectants in different concentrations were diluted with the semen in ratio 1:2 (semen:extender). Diluted semen was manually filled in $0.25 \mathrm{ml}$ straws and sealed. Semen straws were equilibrated for $4 \mathrm{~h}$ at $4{ }^{\circ} \mathrm{C}$. Each straw fraction was further divided into four parts, and subjected to four FP (slow freezing 1, 2, 3 and fast freezing 4). Each FP was done on samples containing 8, 10, and 15\% glycerol and 8, 10, and 15\% DMSO. After each protocol, semen straws were finally deep into liquid nitrogen $-196^{\circ} \mathrm{C}$. After $48 \mathrm{~h}$, the straws were thawed individually to evaluate post/thawed motility, viability, and membrane integrity. The experiment consists of three trials.

Results: At $8 \%$ glycerol concentration, FP1 has significantly $(P>0.05)$ the highest percentage motility (73.33\%) compared to FPs 2, 3, and 4 (56.68, 50.00, and 23.33\% respectively). At 10\% glycerol, FP2 had the highest motility (48.33\%) and HOST (64.00\%). At 15\% glycerol, FP4 (fast freezing) had the highest percentage motility (71.67\%), viability (76.33\%), and HOST (71.67\%). At 8\%, DMSO concentrations FP4 had the highest significant $(P>0.05)$ motility, viability, and HOST. Ten percent and 15\% DMSO revealed no significant $(P>0.05)$ difference in most parameters among all the FPS. DMSO performed better than glycerol irrespective of concentrations in all FPS on most parameters evaluated. (Continued on next page)
\end{abstract}

\footnotetext{
*Correspondence: balogunadedeji001@gmail.com

'Department of Animal Genetics and Breeding, College of Veterinary Science,

Guru Angad Dev Veterinary and Animal Science University, Punjab, India

Full list of author information is available at the end of the article
} 
(Continued from previous page)

Conclusions: Fast freezing performed better with 15\% concentration of glycerol, while slow and fast freezing performed better with 10\% and 15\% DMSO concentrations, which implies that DMSO may serve as better cryoprotectant for poultry semen freezing irrespective of freezing protocols adopted.

Keywords: PB2 rooster, Sperm, Cryoprotectants and freezing protocols, Extender

\section{Background}

Conservation of endangered and economically important species remains a paramount approach for poultry genetic improvement and diversity. Cryopreservation of sperm cells and male gonads seems to be a more promising cryconservation approach for effective preservation of germplasm. The automated semen cryopreservation system has been used for several animal species, including vertebrates (Leite et al. 2010, Abud et al. 2014) and invertebrates (Vuthiphandchai et al. 2007, Bambozzi et al. 2014, Castelo Branco et al. 2014).

The cooling rate is suspected to be the major factor for the reduced survival in conventional cryopreservation methods in poultry species. The freezing tolerance of poultry spermatozoa is the lowest among animal species, due to their characteristic structure of sperm membrane (Blesbois et al. 2005).

However, one of the most critical steps in the cryopreservation of avian semen is to choose the cryoprotectant and its use during the process (Tselutin et al., 1999). Moreover, variety of semen cryopreservation protocols involving different cryoprotective agents (CPAs), packaging methods, and freezing and thawing rates have been developed, firstly in the chicken and then in other domesticated birds, such as turkey, duck, and goose (Donoghue and Wishart, 2000; Blesbois, 2007, 2011).

In addition, various approaches have been made for avian semen cryopreservation such as vitrification in pellet form, rotation method, or slow, programmable freezing and fast freezing. However, adapting this various methods with natural formulated diluents is far-fetched. Semen extenders and holding temperature have been documented to play a significant role in maintaining rooster sperm motility (Dumpala et al. 2006). However, different methods of freezing such as using cryoprotectants like glycerol, N,Ndimethyl acetamide (DMA), and DMSO, slow and rapid freezing-thawing procedures, pellets, vials, and straw packaging have been studied the last few decades (Blesbios $2007,2011)$. Interestingly, coconut water has been tested and proved to maintain the fundamental properties of the natural seminal fluid, showing stability and longevity (important features for industry), replacing chemical and expensive products (Moreira-neto et al. 2009, Purdy et al. 2009; Soares \& Guerra 2009, Bongalhardo, 2013).

Coconut water, the liquid endosperm obtained from immature coconuts, in its natural form is a refreshing and nutritious beverage, widely consumed around the world due to its beneficial health properties (Pummer et al. 2001). Moreover, coconut water plays an important alternative role for oral rehydration and even for intravenous hydration of patients in remote regions (Campbell-Falck et al. 2000) and to protect against induction of myocardial infarction (Anurag and Rajamohan 2003). Coconut water is sterile and slightly acidic natural solution composed of proteins, salts, sugars, vitamins, neutral fats, besides cell division inducers, and various electrolytes, which confer density and $\mathrm{pH}$ compatible with blood plasma, providing nutrients needed to maintain the survival and viability of male and female gametes preserved (Rondon et al. 2008, Lavor \& Câmara 2012). This experiment therefore aimed to test the efficacy and compatibility of different concentrations of glycerol and DMSO supplemented in tris coconut water extender with four different freezing protocols.

\section{Materials and methods}

Experimental site and animal management

The experiment was carried out at the poultry breeding farm and Semen Freezing Laboratory, Directorate of Livestock, Guru Angad Dev Veterinary and Animal Science University, Ludhiana, Punjab, India. Feeding and management of the roosters was done according to recommended management practice of breeder birds.

\section{Diluent preparation}

Fresh coconut fruits were purchased from the market, they were punctured, and water was collected from them into a beaker. The water was decanted, filtered, and collected in a bottle. Tris buffer of $7.2 \mathrm{pH}$ was prepared; coconut water and tris were added $1: 1(\mathrm{v} / \mathrm{v})$. The diluent was divided into six fractions containing two different cryoprotectants (glycerol and DMSO) at different inclusion rate of $8 \%, 10 \%$, and $15 \%$.vis; $8 \%$ glycerol, $10 \%$ glycerol, 15\% glycerol, 8\% DMSO, 10\% DMSO, and 15\% DMSO.

\section{Rooster training for semen collection}

Fifteen roosters of 35 weeks of age were selected for the experiment out of twenty roosters after semen quality screening. Semen samples were collected by combined modified mid back stroke and abdominal massage (Balogun et al. 2015). The roosters were trained for semen collection for 2 weeks; after training period, semen samples were collected 
weekly for processing and cryopreservation procedures for 3 weeks.

\section{Semen preparation, dilution, and cryopreservation}

Pooled semen was evaluated for mass activity and individual progressive motility. Then divided into six fractions and diluted with the extenders containing glycerol and DMSO in different concentrations (8\%, 10\%, and 15\%). Diluted semen was loaded into $0.25 \mathrm{~mL}$ straws with the aid of automatic filling and sealing machine. The semen straws were equilibrated for the duration of $4 \mathrm{~h}$ at $5{ }^{\circ} \mathrm{C}$ in chilling cabinet. Diluted semen were subjected to four different freezing protocols (Table 1). For freezing protocols 1 to 3, a bio-freezer was used while freezing protocol 4 was accomplished using liquid nitrogen in the vapor phase. Subsequently, the straws were and finally stored at - $196^{\circ} \mathrm{C}$ until sperm characteristic evaluation. The experiment consists of three different trials in a complete randomized design. Flow chart of the semen freezing procedure is presented in Fig. 1.

\section{Post-thawed semen evaluation}

Straws were thawed at $5{ }^{\circ} \mathrm{C}$, and semen was evaluated for motility, viability, and membrane integrity with the aid of microscope.

\section{Sperm motility}

A drop of diluted semen was placed on a pre-warmed slide, covered with a cover slip and observed under a light binocular microscope at $\times 400$ magnification. A total of 200 spermatozoa were assessed in different microscopic fields for sperm motility using attached CCTV system and percentage of motile spermatozoa calculated.

\section{Sperm viability}

Sperm viability was assessed by eosin-nigrosine (Blom 1977) staining. Eosin-nigrosin was prepared by mixing
$1.67 \mathrm{~g}$ of eosin and $10 \mathrm{~g}$ of nigrosin in $100 \mathrm{~mL}$ of citrate buffer. Briefly, a thin smear mixture of semen and eosin and nigrosin solution was drawn across the slide and dried. Sperm viability was examined under ( $\times 1000$ magnification) using bright field microscope. Stained/partially stained and unstained sperms were considered as dead and live, respectively. In both cases, about 200 live (white head), partially dead (light pink head), and dead (dark pink head) spermatozoa were counted in different microscopic fields. The percent viability was calculated by using the formula:

$$
\text { Sperm viability }(\%)=\frac{\text { No.of live sperm }}{\text { Total sperm }} \times 100
$$

\section{Plasma membrane integrity}

Sperm plasma membrane integrity was evaluated as described by Jeyendran et al. (1984). Functional integrity of sperm membrane was evaluated by hypoosmotic swelling test. The hypo-osmotic solution (50 $\mathrm{mOsm} / \mathrm{L}$ ) was prepared by dissolving $4.9 \mathrm{~g}$ of sodium citrate and $8.77 \mathrm{~g}$ of fructose in $1 \mathrm{~L}$ of double distilled water (DDW). In brief, $100 \mu \mathrm{L}$ of semen was mixed with $1.0 \mathrm{~mL}$ of hypo-osmotic solution and incubated at $37{ }^{\circ} \mathrm{C}$ for $1 \mathrm{~h}$. Simultaneously, $100 \mu \mathrm{L}$ of semen was incubated in $1.0 \mathrm{~mL}$ of phosphate buffer saline (control) under similar conditions. A $10 \mu \mathrm{L}$ of incubated semen (HOST or control) was placed on separate glass slides and covered with a cover slip. The semen was observed under bright field microscope $(\times 10, \times$ 40 magnification). About 200 spermatozoa were counted separately in control and hypo-osmotic solution in different microscopic fields for their swelling (coiled tail) which indicate intact plasma membrane. The number of coiled tail spermatozoa in control was deducted from that in hypo-osmotic solution, and the resultant figure was taken as the HOS-reactive sperm.

Table 1 Freezing protocols

\begin{tabular}{|c|c|c|c|c|}
\hline Protocols & Freezing protocol 1 & Freezing protocol 2 & Freezing protocol 3 & Freezing protocol 4 \\
\hline Cryo-vials type & $0.25 \mathrm{~mL}$ straws & $0.25 \mathrm{~mL}$ straws & $0.25 \mathrm{~mL}$ straws & $0.25 \mathrm{~mL}$ straws \\
\hline Diluents & Tris coconut water & Tris coconut water & Tris coconut water & Tris coconut water \\
\hline Cryoprotectant type & Glycerol and DMSO & Glycerol and DMSO & Glycerol and DMSO & Glycerol and DMSO \\
\hline $\begin{array}{l}\text { Cryoprotectant } \\
\text { concentrations }\end{array}$ & 8,10, or $15 \%$ & 8,10, or $15 \%$ & 8,10, or $15 \%$ & 8,10 , or $15 \%$ \\
\hline Dilution rate & $1: 2$ & $1: 2$ & $1: 2$ & $1: 2$ \\
\hline Equilibration time & $4 \mathrm{~h}$ at $5^{\circ} \mathrm{C}$ & $4 \mathrm{~h}$ at $5^{\circ} \mathrm{C}$ & $4 \mathrm{~h}$ at $5^{\circ} \mathrm{C}$ & $4 \mathrm{~h}$ at $5^{\circ} \mathrm{C}$ \\
\hline Freezing rate & $\begin{array}{l}-3^{\circ} \mathrm{C} / \mathrm{min} \text { until }-50^{\circ} \mathrm{C} \\
-50^{\circ} \mathrm{C} / \mathrm{min} \text { to }-130^{\circ} \mathrm{C} \\
\text { finally }-196^{\circ} \mathrm{C}\end{array}$ & $\begin{array}{l}4{ }^{\circ} \mathrm{C} / \mathrm{min} \text { until }-50^{\circ} \mathrm{C}, \\
\text { cool from }-50 \text { to }-150^{\circ} \mathrm{C} \\
\text { at a rate of } 50^{\circ} \mathrm{C} / \mathrm{min}, \\
\text { finally }-196^{\circ} \mathrm{C}\end{array}$ & $\begin{array}{l}1^{\circ} \mathrm{C} / \mathrm{min}, \text { to }-20^{\circ} \mathrm{C}-20 \\
\text { to }-80^{\circ} \mathrm{C} \text { at a rate of } \\
20^{\circ} \mathrm{C} / \mathrm{min} \text {, finally }-196{ }^{\circ} \mathrm{C}\end{array}$ & $\begin{array}{l}\text { Vapor freezing at }-50^{\circ} \mathrm{C} \\
\text { for } 12 \text { min, then immersed } \\
\text { directly into liquid nitrogen } \\
\text { at }-196{ }^{\circ} \mathrm{C}\end{array}$ \\
\hline
\end{tabular}




\section{Tris Coconut-water diluent preparation}

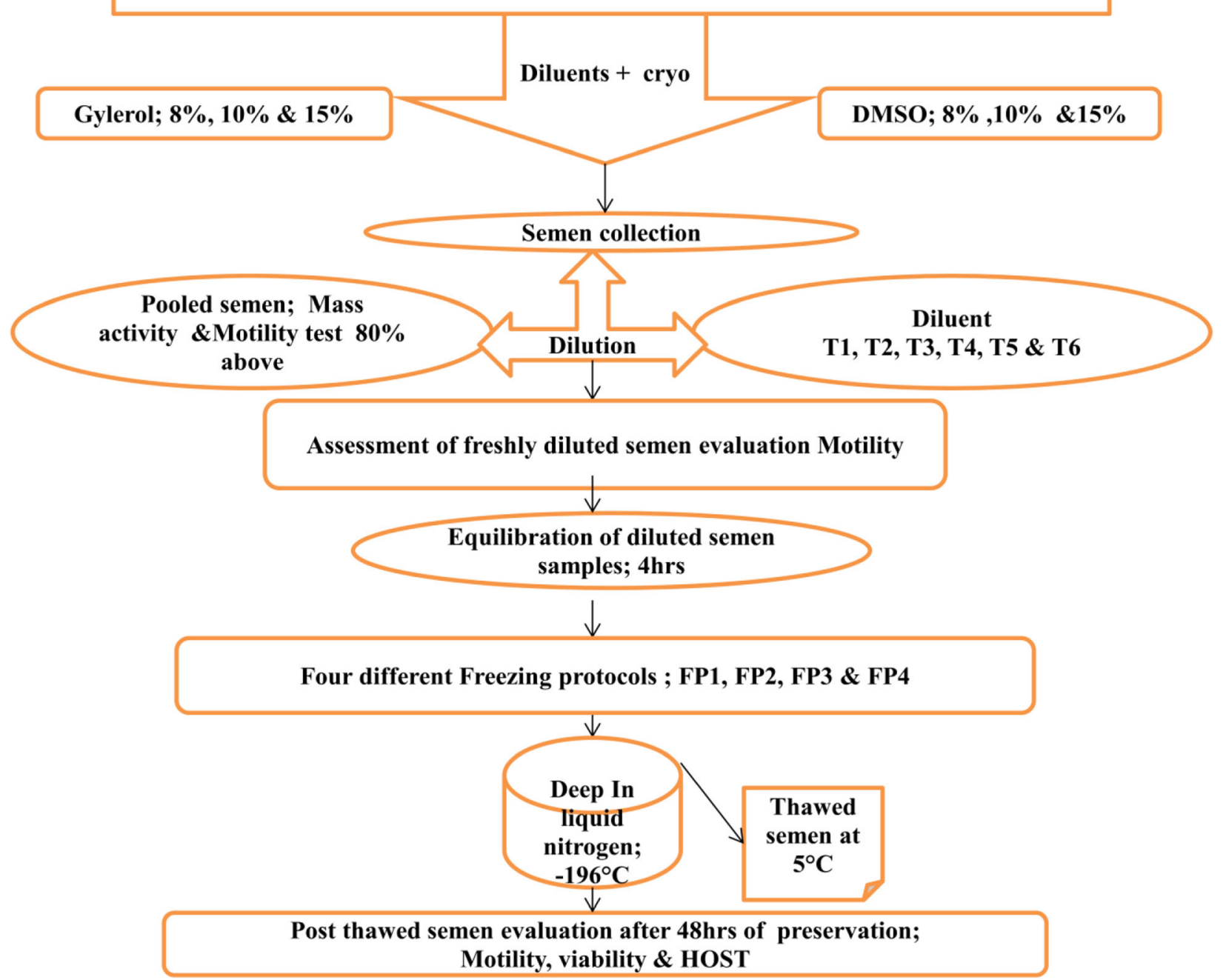

Fig. 1 Flow chart for rooster semen different freezing protocols for cryopreservation

\section{Statistical analysis}

Observations were subjected to statistical analysis using ANOVA; means were separated with Duncan multiple range test.

\section{Results}

\section{Effects of freezing protocols using different glycerol} concentrations

Effects of freezing protocols (FP) on frozen-thawed rooster semen cryopreserved with tris coconut water extender (TCWE) containing different concentrations of glycerol are presented in Table 2. The glycerol at $8 \%$ concentration in TCWE used for freezing revealed that FP1 had significantly $(P<0.05)$ the highest post-thawed motility $(73.33 \%)$ when compared to FPs 2, 3, and 4 (56.68, 50.00, and 23.33\%, respectively). No significant difference $(P>0.05)$ was observed in viability and membrane integrity among the FPs 1 to 4 . Ten percent glycerol concentration in TCWE revealed no significant difference $(P>0.05)$ among the FPs except for motility that was significantly higher $(P<0.05)$ in FP2 (48.33\%) compared to FP3 (40.00\%) and FP4 (36.67\%). At $15 \%$ glycerol concentration in TCWE, the FP4 showed significantly the highest $(P<0.05)$ post-thawed motility (71.67) when compared to other freezing protocols FP1, FP2, and FP3 (26.67\%, 38.33\%, and 33.33\%, respectively). Moreover, viability and membrane integrity were also higher $(P<0.05)$ in FP4 $(76.33 \%$ and $71.67 \%$ respectively) when compared with FP3 but were not significantly different from FP1 (65.00\% and 63.67\%, respectively) and FP2 (51.33\% and $60.00 \%$, respectively). 
Table 2 Effects of freezing protocols on frozen thawed rooster semen cryopreserved with coconut water extender containing different concentrations of glycerol and DMSO

\begin{tabular}{|c|c|c|c|c|c|c|c|}
\hline \multirow[b]{2}{*}{ Cryoprotectants } & \multirow[b]{2}{*}{ Concentrations } & \multicolumn{6}{|c|}{ Freezing Protocols } \\
\hline & & Parameters & FP1 & FP2 & FP3 & FP4 & SEM \\
\hline \multirow[t]{9}{*}{ Glycerol } & $(8 \%)$ & Motility (\%) & $73.33^{\mathrm{a}}$ & $56.68^{\mathbf{b}}$ & $50.00^{\mathbf{b}}$ & $23.33^{c}$ & 5.57 \\
\hline & & Viability (\%) & $68.33^{\mathbf{a b}}$ & $72.00^{a}$ & $67.67^{\mathrm{ab}}$ & $56.33^{\mathbf{b}}$ & 2.49 \\
\hline & & Host (\%) & 67.67 & 67.67 & 59.33 & 59.33 & 2.84 \\
\hline & $(10 \%)$ & Motility (\%) & $43.33^{\mathbf{a b}}$ & $48.33^{a}$ & $40.00^{\mathbf{b}}$ & $36.67^{\mathbf{b}}$ & 1.56 \\
\hline & & Viability (\%) & 68.33 & 71.67 & 63.67 & 74.38 & 1.79 \\
\hline & & Host (\%) & 56.67 & 64.00 & 58.00 & 62.67 & 2.25 \\
\hline & $(15 \%)$ & Motility (\%) & $26.67^{c}$ & $38.33^{\mathbf{b}}$ & $33.33^{\mathbf{b c}}$ & $71.67^{\mathrm{a}}$ & 5.31 \\
\hline & & Viability (\%) & $65.00^{\mathbf{a b}}$ & $63.67^{\mathrm{ab}}$ & $58.00^{\mathbf{b}}$ & $76.33^{\mathrm{a}}$ & 2.66 \\
\hline & & Host (\%) & $51.33^{\mathrm{ab}}$ & $60.00^{\mathbf{a b}}$ & $50.67^{\mathbf{b}}$ & $71.67^{\mathrm{a}}$ & 3.63 \\
\hline \multirow[t]{9}{*}{ DMSO } & $(8 \%)$ & Motility (\%) & $26.67^{c}$ & $35.00^{\mathbf{b c}}$ & $40.00^{\mathbf{a b}}$ & $50.00^{a}$ & 2.98 \\
\hline & & Viability (\%) & $64.67^{\mathbf{b}}$ & $65.67^{\mathbf{b}}$ & $54.67^{\mathbf{b}}$ & $82.00^{\mathbf{a}}$ & 3.49 \\
\hline & & Host (\%) & $57.67^{\mathbf{b c}}$ & $64.33^{\mathbf{a b}}$ & $45.00^{c}$ & $76.33^{\mathbf{a}}$ & 3.99 \\
\hline & $(10 \%)$ & Motility (\%) & $71.67^{\mathbf{b}}$ & $75.00^{\mathbf{a b}}$ & $76.67^{\mathrm{a}}$ & $78.33^{\mathrm{a}}$ & 0.97 \\
\hline & & Viability (\%) & $76.33^{\mathbf{b}}$ & $82.00^{\mathbf{a b}}$ & $80.67^{\mathbf{a b}}$ & $83.67^{\mathrm{a}}$ & 1.19 \\
\hline & & Host (\%) & 77.33 & 81.67 & 77.33 & 84.33 & 1.51 \\
\hline & (15\%) & Motility (\%) & 70.00 & 70.00 & 71.33 & 71.67 & 0.65 \\
\hline & & Viability (\%) & $77.33^{\mathbf{b}}$ & $84.33^{\mathbf{a b}}$ & $88.00^{a}$ & $81.67^{\mathbf{a b}}$ & 1.66 \\
\hline & & Host (\%) & $75.00^{\mathbf{b}}$ & $81.33^{\mathbf{a b}}$ & $83.33^{a}$ & $79.33^{\mathbf{a b}}$ & 1.37 \\
\hline
\end{tabular}

Superscripts indicate significant difference at $5 \%$ level within the columns (a-c) SEM standard error of mean for freezing protocols

\section{Effects of freezing protocols using different DMSO concentrations}

Effects of freezing protocols (FP) containing different concentrations of DMSO are presented in Table 2. The DMSO at $8 \%$ concentration in TCWE revealed that FP4 showed significantly the highest $(P<0.05)$ post-thawed motility $(50.00 \%)$ when compared with FP1 and FP2. FP4 also showed higher viability $(82.00 \%)$ when compared to other groups and higher membrane integrity (76.33\%) when compared with FP1and FP3. At 10\% and 15\% DMSO concentration in TCWE, no significant difference $(P>0.05)$ was observed among the FPs. However, FP4 had the highest motility, viability, and membrane integrity values at 10\% DMSO concentration while FP3 also had the highest viability and membrane integrity values at $15 \%$ DMSO concentration.

\section{Effects cryoprotectant concentration on freezing protocols}

With respect to cryoprotectant concentration regardless of the cryoprotectant type (Figs. 2, 3, and 4), our results revealed that the cryoprotectant at $15 \%$ concentration using FP4 (fast freezing) had above $70.00 \%$ post-thawed motility, while up to $10 \%$ concentration is desirable for slow freezing protocols 1,2 , and 3 as they increase in percentage post-thawed motility from above $30.00 \%$ in $8 \%$ concentration to above $50.00 \%$ in $10 \%$ concentration (Fig. 2). Viability percentage increases with cryoprotectant concentration in different FPs except for slightly dropped in viability observed in FP2 and FP3 at 15\% concentration (Fig. 3). Membrane integrity increases with cryoprotectant concentration in FP4 but slightly dropped at $15 \%$ concentration in FP1, FP2, and FP3 (Fig. 4).

\section{Discussion}

A successful cryopreservation is affected by optimization of all steps during the process including semen collection and dilution, equilibration with a suitable cryoprotectant, freezing in liquid nitrogen vapor, storage in liquid nitrogen, and thawing before insemination (Sood et al. 2012). Determining and identifying efficient freezing protocols with respect to the type and concentration of appropriate cryoprotectants may be proactive measures towards successful cryopreservation of poultry semen and ditto germplasm conservation. Freezing protocol 1 and FP2 (slow freezing) having better post-thawed sperm parameter performance most especially in motility and viability with $8 \%$ glycerol initial concentration is an indication that glycerol at reduced concentration is more compatible with slow freezing for cryopreservation of poultry semen. Our 


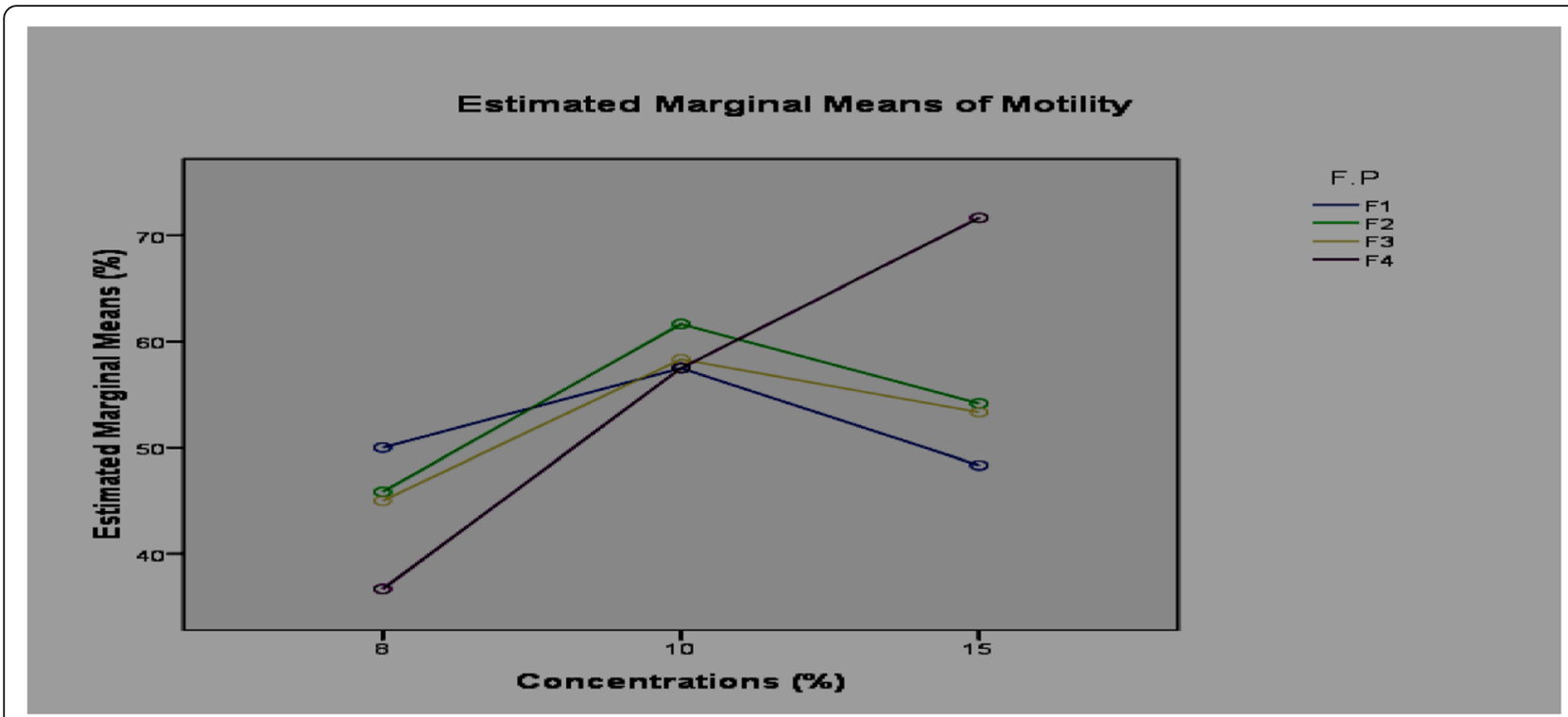

Fig. 2 Effect of different freezing protocols on motility of post thawed rooster semen on different concentrations of cryoprotectants

result is in agreement with the work of Reda et al. (2017) who concluded that $\mathrm{CW}$-enriched media with $4 \%$ glycerol addition (CWCG-4) is safe to be used as an extender in bull semen preservation because it is a sterile liquid, so it can be used without addition of antibiotics to the extender, as antibodies have to some extent hazardous effect on spermatozoa.

Higher concentration of cryoprotectants (10 and 15\% $\mathrm{v} / \mathrm{v}$ ) that shows no much differences except in motility at $15 \%$ concentration revealed that at higher concentration of cryoprotectant sperm cells becomes more tolerant irrespective of freezing protocols adopted for cryopreservation procedures. Since motility is one of the many important attributes of a fertile spermatozoon, our result is therefore in agreement with Peña Martinez (2004) who reported that 7-8\% glycerol may deem to be sufficient for poultry semen freezing. Moreover, the concentration of glycerol to be used depends upon the semen diluent. The higher the percentage of egg yolk in a diluent, the higher the amount of glycerol to be added (Maule 1962). Reda et al. (2017) reported that CW extender with glycerol $4 \%, 6 \%$, and $8 \%$ improved sperm membrane integrity (HOST \%) of cooled semen, and the superior result was obtained in CW with $4 \%$ glycerol.

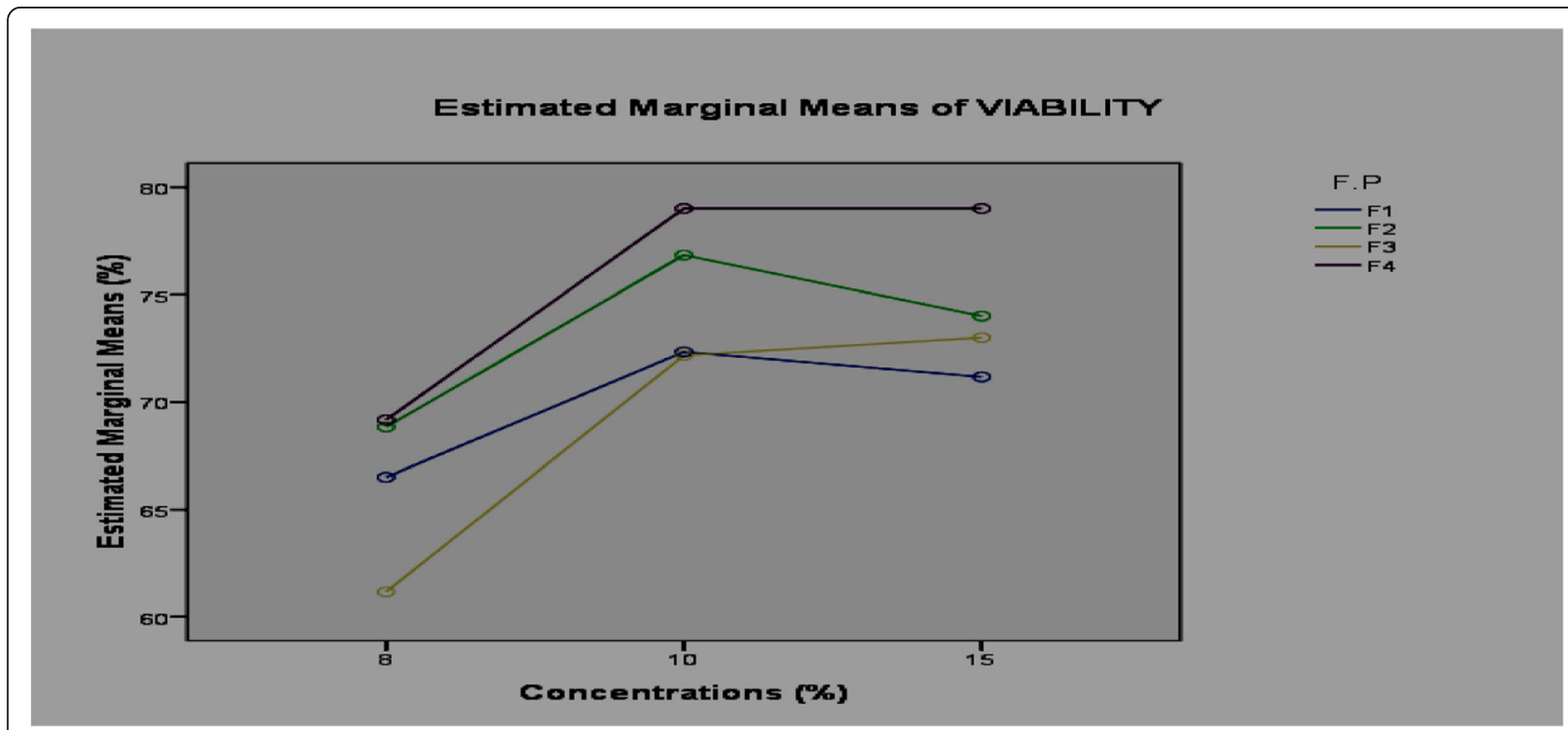

Fig. 3 Effect of different freezing protocols on viability of post-thawed rooster semen on varying concentrations of cryoprotectants 


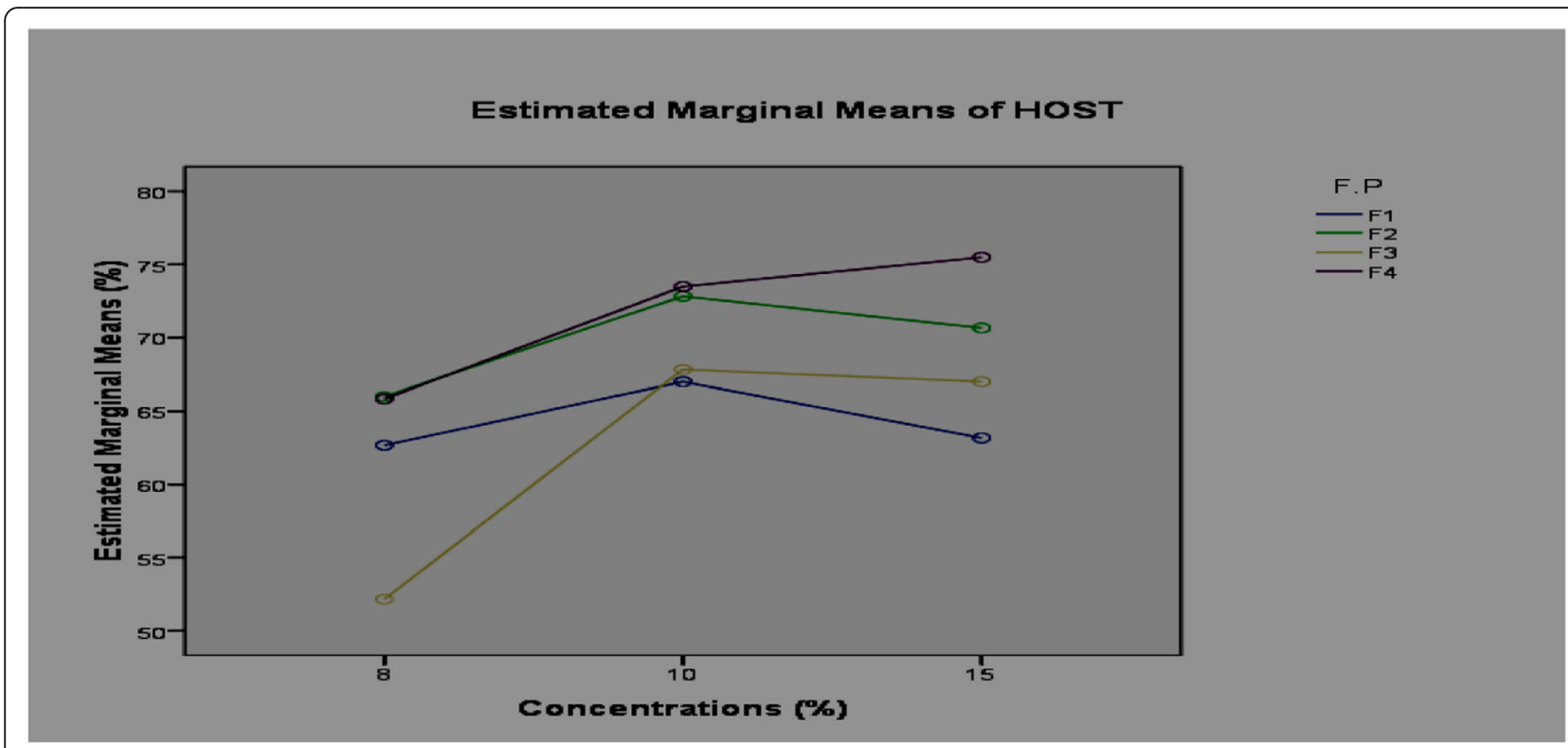

Fig. 4 Effect of different freezing protocols on hypo-osmotic swelling test of post thawed rooster semen on varying concentrations of cryoprotectants

Glycerol penetrates the sperm cell and dehydrates the cell partially, thereby reducing the risk of water crystallization (Bearden et al. 2004). Silva et al. (2015) and Cardoso et al. (2006) also concluded that CW containing glycerol is recommended to achieve satisfactory post-freezing quality of boar semen.

The better performance of DMSO in all freezing protocols and mostly with fast freezing revealed the tolerance of DMSO with different freezing procedures and so deemed to be a better cryoprotectant compared to glycerol in poultry semen cryopreservation. However, DMSO was observed to have best performance with FP4 (fast freezing) regardless of the DMSO concentrations. Furthermore, fast freezing protocol was observed to be appropriate for freezing of rooster semen, most especially with high concentration of cryoprotectants as there is no much difference between it and slow freezing. Besides, it is easy to carry-out with less costly equipments and technical knowhow.

Our observation is in accordance with Mazur et al. (1972) and Medeiros et al. (2002) who reported that cell freezing should take place as quickly as possible to avoid the effects of cryoprotectants but also slowly enough for cells to dehydrate. Costa et al. (2017) also reported a comparison of the cooling rates between the conventional and automated systems showing that the automated system $\left(0.5^{\circ} \mathrm{C} \mathrm{min}{ }^{-1}\right)$ might have cooled too slowly, thus leaving the cryoprotectant solution in contact with the semen for too long before freezing, which was lethal to sperm. However, according to Santos (2000), if freezing is slow, damage is primarily caused by excessive dehydration or extensive ice formation outside the cells. In these cases, membrane rupture, solutes concentrations in the cytoplasm reaching toxic levels, and nucleic acid and membrane denaturation might occur.

In addition, higher concentration of cryoprotectant regardless of the type also revealed a higher cryoprotectant dependable better activity performance of sperm cells with respect to post-thawed semen quality; this was evident in $10 \%$ and $15 \% \mathrm{v} / \mathrm{v}$. This implies that increasing cryoprotectant concentration is favorable for most freezing protocols in this study up to $15 \%$. Benson et al. (2012) emphasized that an important factor to be considered is the high concentration of cryoprotectants because it has been shown to be cytotoxic. However, toxicity of cryoprotectants deemed that toxicity of cryoprotectants is permeability and molecular weight dependent.

\section{Conclusion}

Fast freezing performed better with 15\% concentration of glycerol, and slow freezing performed better with $8 \%$ glycerol, while slow and fast freezing performed better with $10 \%$ and $15 \%$ DMSO concentrations, which implies that DMSO may serve as better cryoprotectant for poultry semen freezing irrespective of freezing protocols adopted, although each procedure has its own inherent peculiar variabilities, such as type of diluent, dilution rate, cooling rate, nature and concentrations of cryoprotectant, freezing protocols, choice of packaging (semen straws or pellets) and thawing procedure. 


\section{Abbreviations}

CW: Coconut water; DDW: Double-distilled water; DMSO: Dimethylsulfoxide; FP: Freezing protocol; HOST: Hypoosmotic swelling test; pH: Pondus hydrogen; TCWE: Tris coconut water extender; Fig.: Figure

\section{Acknowledgements}

Not applicable.

\section{Authors' contributions}

BAS designed and carried out the research and first draft of the manuscript. $\mathrm{RN}$ and RC supervised the freezing protocols and statistical analysis. AJ, MV, and AK did the semen analysis and final manuscript draft. The authors read and approved the final manuscript.

\section{Funding}

India Council of Agricultural Research and Directorate of Livestock GADVASU

\section{Availability of data and materials}

All data generated or analyzed during this study are included in this published article [and its Supplementary information files]

\section{Ethics approval and consent to participate}

Not applicable

\section{Consent for publication}

Not applicable

\section{Competing interests}

The authors declare that they have no competing interests.

\section{Author details}

'Department of Animal Genetics and Breeding, College of Veterinary Science, Guru Angad Dev Veterinary and Animal Science University, Punjab, India. ${ }^{2}$ Department of Veterinary Gynecology and Obstetrics, College of Veterinary Science, Guru Angad Dev Veterinary and Animal Science University, Punjab, India.

Received: 8 January 2020 Accepted: 25 June 2020

Published online: 13 July 2020

\section{References}

Abud COG, Abud LJ, Oliveira Neto JC, Dode MAN, Sereno JRB, Martins CF (2014) Comparison between the conventional and automated systems of semen bovine cryopreservation. Ciência Animal Brasileira 15:32-37

Anurag P And Rajamohan T. (2003) Cardioprotective effect of tender coconut water in experimental myocardial infarction. Plant Food Hum Nutr 58:1-12

Balogun AS, Jimoh OA, Mustapha TB, Olapoju GO, Ojo JA (2015) Comparative semen characteristics of Nigerian indigenous cock and exotic strains of domestic fowl. Nigerian J Anim Sci 17(2):148-153.

Bambozzi A, Mattos LA, Mello MRB, Oshiro LMY (2014) Post-mortem spermatophore and sperm cryopreservation of the white shrimp Litopenaeus schmitti. Boletim do Instituto de Pesca 40:49-60

Bearden HJ, Fuquay JW, Willard ST 2004. Applied animal reproduction. Pearson Education, Inc. New Jersey. 6th Edition, p.109-27.

Benson JD, Woods EJ, Walters EM, Critser JK (2012) The cryobiology of spermatozoa. Theriogenology 78:1682-1699

Blesbois E (2007) Current status in avian semen cryopreservation. World's Poultry Scienc Journal. 63:213-222

Blesbois E (2011) Freezing avian semen. Avian. Biology. Res. 4:52

Blesbois E, Grasseau I, Seigneurin F (2005) Membrane fluidity and the ability to survive cryopreservation in domestic bird spermatozoa. Reproduction. 129: $371-378$

Blom E. 1977 Sperm morphology with reference to bull fertility. In Proc. First Al India Symposium on Animal Reproduction. Ludhiana. 61-81

Bongalhardo DC (2013) Produção e preservação do sêmen de galos. Revista Brasileira de Reprodução Animal 37:131-135

Campbell-Falck D, Thomas T, Falck TM, Tutuo N And Clem K. (2000) The intravenous use of coconut water. Am J Emerg Med 18:108-111

Cardoso RCS, Silva AR, da Silva LDM (2006) Comparison of two dilution rates on canine semen quality after cryopreservation in a coconut water extender. Animal Reproduction Science 92:384-391
Castelo Branco T, Bambozzi A, Mello MRB, Oshiro LMY (2014) Cryopreservation and sperm storage of the white shrimp. Boletim do Instituto de Pesca 40:17-22

Costa TV, Lidia Oshiro MY, Mattos LA, Laura López Greco S, Melo EP, Flor HR (2017) Toxicity, freezing and cold storage tests of native species semen. B Inst Pesca, São Paulo 43:334-346, https://doi.org/10.20950/1678-2305.

Donoghue AM, Wishart GJ (2000) Storage of poultry semen. Animal. Reproduction. Science 62:213-232

Dumpala PR, Parker HM, Mcdaniel CD (2006) The effect of semen storage temperature and diluent type on the sperm quality index of broiler breeder semen. Int J Poultry Sci. 5:838-845

Jeyendran RS, Van Der Ven HH, Perez-Pelaez M, Crabo BG, Zaneveld LD (1984) Development of an assay to assess the functional integrity of human sperm membrane and its relationship to other characteristics. J Reprod Fertil 70: 219-228

Lavor CT, Camara SR (2012) Biotecnologia Do Sêmen E Inseminação Artificial Em Aves. Ciência Animal 22:66-81

Leite TG, Vale Filho VR, Arruda RP, Andrade AFC, Emerick LL, Zaffalon FG, Martins JA De Andrade VJ. (2010) Effects of extender and equilibration time on postthaw motility and membrane integrity of cryopreserved Gyr bull semen evaluated by CASA and flow cytometry. Anim Reprod Sci 120:31-38

Maule JP (1962) The semen of animals and artificial insemination. Common Wealth Agricultural Bureaux England.

Mazur P, Leibo SP, Chu EH (1972) A two-factor hypothesis of freezing injury. Evidence from Chinese hamster tissue-culture cells. Experimental Cell Research 71:345-355

Medeiros CM, Forell F, Oliveira AT, Rodriques JL (2002) Current status of sperm cryopreservation: why isn't it better? Theriogenology 57:327-344

Moreira-Neto JJS, Gondim JO, Raddi MSG, Pansani CA (2009) Viability of human fibroblasts in coconut water as a storage medium. Int Endodontic J 42:827-830

Peña Martínez A I. Canine fresh and cryopreserved semen evaluation. 2004 Animal

Pummer S, Heil P, Maleck W, Petroianu G (2001) Influence of coconut water on homeostasis. Am J Emerg Med. 19:287

Purdy PH, Song Y, Silversides FG, Blackburn H.D. Evaluation of glycerol removal techniques, cryoprotectants, and insemination methods for cryopreserving rooster sperm with implications of regeneration of breed or line or both. Poultry Science, 2009;88:2184-2191

Reda IE, Walid SE, Gamal ADA (2017) Cryopreservation of cattle semen using coconut water extender with different glycerol concentrations. Asian Pacific Journal of Reproduction:279-282

Rondon RMM, Rondon FCM, Nunes JF, Alencar AA, Sousa FM, Carvalho MAM Uso da água de coco em pó (ACP®) em diferentes temperaturas como diluente de espermatozóides de capote (Numida meleagris). Revista Brasileira de Saúde e Produção Animal [online], 2008;9:848-854

Santos IRI. Cryopreservation: potential and perspectives for plant germplasm conservation. Brazilian Journal of Plant Physiology, 2000;12(especial edition): $70-84$

Silva CG, Cunha ER, Blume GR, Malaquias JV, Bào SN, Martins CF (2015) Cryopreservation of boar sperm comparing different cryoprotectants associated in media based on powdered coconut water, lactose and trehalose. Cryobiology 70:90-94

Soares AT, Guerra MMP (2009) Efeitos da criopreservação sobre a viabilidade espermática. Tecnologia e Ciência Agropecuária 3:53-63

Sood S, Malecki IA, Tawang A, Martin GB (2012) Sperm viability, motility and morphology in emus (Dromaius novaehollandiae) are independent of the ambient collection temperature but are influenced by storage temperature. Theriogenology. 77:1597-1604

Tselutin K Seigneurin F, Blesbois E (1999) Comparison of cryoprotectants and methods of cryopreservation of fowl spermatozoa. Poultry Science 78:586-590

Vuthiphandchai V, Nimrat S, Kotcharat S, Barth AN (2007) Development of a cryopreservation protocol for long-term storage of black tiger shrimp (Penaeus monodon) spermatophores. Theriogenology 68:1192-1199

\section{Publisher's Note}

Springer Nature remains neutral with regard to jurisdictional claims in published maps and institutional affiliations. 